\title{
Localized Heat Treatment to Improve the Formability of Steel Pipes for Hydraulic Applications: Process Design and Mechanical Characterization
}

\section{Luigi Bruno ( $\sim$ luigi.bruno@unical.it)}

University of Calabria: Universita della Calabria https://orcid.org/0000-0002-6745-0466

\section{Santo Canto}

University of Calabria: Universita della Calabria

Luciano Luciani

University of Calabria: Universita della Calabria

\section{Research Article}

Keywords: Localized heat treatment, Induction heat treatment, Micro囚indentation test, Tensile test, Digital image correlation

Posted Date: July 9th, 2021

DOl: https://doi.org/10.21203/rs.3.rs-613492/v1

License: (c) (1) This work is licensed under a Creative Commons Attribution 4.0 International License. Read Full License

Version of Record: A version of this preprint was published at The International Journal of Advanced Manufacturing Technology on November 11th, 2021. See the published version at https://doi.org/10.1007/s00170-021-08321-7. 


\title{
Localized heat treatment to improve the formability of steel pipes for hydraulic applications: process design and mechanical characterization
}

\author{
Luigi Bruno ${ }^{a} *$, Santo Canto ${ }^{b}$ Luciano Luciani ${ }^{b}$
}

\author{
${ }^{a}$ Department of Mechanical, Energy and Management Engineering, University of Calabria, Via Bucci 44C, 87036 Rende (CS), Italy

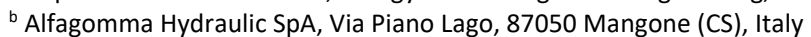 \\ * ORCID: 0000-0002-6745-0466, emial: luigi.bruno@unical.it
}

\begin{abstract}
In the present work, authors have demonstrated how a localized induction heat treatment can be advantageously applied, controlled and mechanically characterized on a specific part - i.e. on steel hose fittings for hydraulic applications. More specifically, the study shows how this specific type of heat treatment facilitates the acquisition of significant localization effects on mechanical properties, and how such a treatment could act as a powerful tool for material optimization in diverse applications. The instrumented micro-indentation test was adopted as the investigation method for mechanical characterization and, due to the reduced amount of material required for the test, has the double advantage of retrieving potential spatial gradients of the mechanical properties without causing permanent damage to the entirety of analyzed parts. The measurement of both the Vickers hardness and plastic work required to make the indentation that would be necessary to quantify the strength and ductility capability of the parts' material. In addition, a customized tensile test, based on the strains measurement obtained through an optical full-field method - i.e. Digital Image Correlation (DIC) - was developed with the aim of identifying and quantifying the correlation between the material properties attainable through a conventional tensile test and those measured by the instrumented micro-indentation test. Finally, it was demonstrated that the proposed customized tensile test, due to the localized heat treatment, is capable of retrieving potential spatial gradients of material properties.
\end{abstract}

\section{Keywords}

Localized heat treatment; Induction heat treatment; Micro-indentation test; Tensile test; Digital image correlation.

\section{Declarations}

Funding: This study received the funding from Alfagomma Hydraulic SpA.

Conflicts of interest/Competing interests: The authors declare no conflict or competing interests. Availability of data and material: The authors confirm that the data and material supporting the findings of this work are available within the article.

Code availability: Not applicable. No software requiring license was used.

Authors' contributions:

Luigi BRUNO: Conceptualization, methodology, experimental test, data-processing, writing, editing Santo CANTO: specimens preparation, reviewing Luciano LUCIANI: specimens preparation, reviewing, supervision

Ethics approval: The article follows the guidelines of the Committee on Publication Ethics (COPE) and involves no studies on human or animal subjects.

Consent to participate: Not applicable. The article involves no studies on humans.

Consent for publication: Not applicable. The article involves no studies on humans. 


\section{Introduction}

Heat treatments always represented a powerful tool to improve the performance of the materials in several industrial applications, allowing to attain specific mechanical properties without modifying the chemical composition of the materials [1]. One of the main drawbacks arising from the application of this type of treatment in industrial environment is the high cost due to the energy and time requirements. In fact, in its standard implementation, a heat treatment requires to fit the whole part to be treated in an oven, which implies a maximum volume to be treated, and a sufficient long time of process, increasing with the temperature to be reached (and maintained) and the thermal resistance of the system. The use of a standard chamber equipped with a single door make the process discontinuous, with an additional increase of cost and time, frequently avoided in industry by the use of continuous oven. Although, even by this solution, the issues related to maximum volume processable and heating and cooling times persist. In addition, if only local properties have to be obtained, the fact that the whole part is contained in the oven implies a difficult design of the whole process, which not always allows an accurate result.

In this picture, according to the different needs arising from the quite wide variety of industrial requirements, innovative localized heat treatments were proposed and developed. Among all of them, the induction-based heat treatments [2-4] allowed to attain several advantages in different applications, both in industrial environment and in research and development experiments.

Thanks to their high magnetic susceptibility, iron-based materials (and in particular steels) are the most common materials which this type of heat treatment in applied on. Several studies demonstrated how microstructure and mechanical properties can be significantly modified by induction heat treatments applied to a wide range of iron-based materials and applications. Different research papers investigated the influence of operating parameters on the mechanical properties, with the focus on bulk materials [5-7], superficial aspects [8,9] and welded parts [10, 11]. Guo et al. [12] showed how the combination of the induction heat and surface peening treatments improved the yield strength without significantly impacting the ductility of pure iron. Bao et al. [13] designed a specific induction heat treatment for automotive industry capable to confer heterogeneous mechanical properties with the aim of optimizing the performance of the treated parts.

Microstructural and mechanical properties were similarly modified and improved on other types of materials, like nickel-based coatings [14] and titanium alloys [15, 16]. Furthermore, several other types of applications different from the heat treatments were carried out by means of the induction heating, like melting and casting of copper [17] and nickel alloys [18], technological processes implying large deformations [19, 20], and innovative welding processes [21, 22].

By the present paper, authors proposed experimental methods to quantify the impact on the mechanical properties of a localized induction heat treatment performed on steel hose fittings for hydraulic applications. In particular, the focus was on straight pipes, obtained by machining a full cylindrical bar, which have to be bent in order to form a $90^{\circ}$ angle. The experimental methods developed to investigate about mechanical properties modifications were two: instrumented microindentation tests and tensile tests supplied with optical equipment for the strain field measurement. The diffusion of instrumented micro-indentation test for mechanical characterization is mainly due to the work of Oliver and Pharr [23] in the 90s, who demonstrated by several numerical and experimental studies how properties like stiffness, strength and ductility can be retrieved by monitoring the load/displacement curve of an indentation test. Beside the information obtained in terms of mechanical properties, the great benefit offered by this approach resides in the high localized volume of the material involved in the test, which implies two important advantages: the single test provides the local mechanical properties, therefore the method can be used to retrieve spatial gradients of the properties; the indentation test can be considered as a semi-destructive or 
even non-destructive test, depending on how critically stressed is the area where the indentation is executed. All these strengths encouraged the use of this approach, bringing the release of standards $[24,25]$ and the development of commercial devices [26, 27].

On the other hand, the combination of Digital Image Correlation (DIC) methods [28] and standard tensile tests carried out on portion of pipes allowed to identify more accurately some mechanical properties and their spatial gradients. In fact, the full-field feature of this displacement measurement method allows the accurate quantification of the strains on a high number of points, theoretically equal to the pixel number of the acquired images. In practice, considering how the correlation algorithm works, the noise of the acquisition chain and other error sources, the number of points where the strains are accurately and successfully measured is smaller than the total number of pixels, but still considerably bigger than the amount of information attainable by conventional method - e.g. strain gages, extensometers.

Finally, we demonstrated how a relationship can be determined between the tensile test and microhardness properties. In particular, stress and strain at the necking limit resulted to be correlated to the plastic deformation work of indentation, whereas the mathematical relation can be assumed linear, provided that the range of the considered values is not too wide. The evaluation of this type of relationship has the advantage to provide important mechanical properties and their gradients typically obtained by expensive and destructive tests - i.e. tensile test - by quite less invasive and cheaper experimental procedures - i.e. indentation tests -, easily implementable in industrial environment without the need of highly skilled operators.

Within this framework, the impact on the mechanical properties of induction-based heat treatments applied on steel hose fittings was suitably investigated and quantified. The study showed how the developed methods allow to quantify and control the properties' magnitude and gradient, with the aim to advantageously fit the parts in the whole production cycle.

\section{Materials and methods}

The analyzed parts are rectilinear steel pipes to be curved permanently without damage or failure arising during the cold bending process, and, at the same time, the strength of the original material should not worsen. In this scenario, due to the large strains occurring on the portion to be bent, a ductility of the original material has to be increased, whereas the tensile strength and related properties should not be significantly impacted by the subsequent mechanical processes and heat treatments.

The original material is a cold drawn bar of $11 \mathrm{SMnPb} 30$ steel with a Carbon average percentage of $0.07 \%$. The main alloy elements are: Manganese $(\approx 1.0 \%)$, Sulphur $(\approx 0.3 \%)$ Phosphor $(\approx 0.2 \%)$ and Lead $(\approx 0.3 \%)$. This composition confers to the material good high-speed machinability and a limited weldability. For bars whose diameter is less than $15 \mathrm{~mm}$, the guaranteed minimum tensile strength and the Rockwell B hardness are $490 \mathrm{MPa}$ and $79.5 \mathrm{HRB}$, respectively.

The bars to be curved by a cold process were machined in pipe shapes of different sizes and subjected to the induction heat treatments. In order to quantify the variation and the gradient of the mechanical properties, instrumented micro-indentation tests and tensile tests integrated with optical equipment for the strain field measurement were applied.

\subsection{The localized induction heat treatment}

The induction machine consists of a generator, control electronics and connectors for heating heads. The generator can work in the low/middle frequency range up to about $200 \mathrm{~Hz}$ with an input current up to $17 \mathrm{~A}$, and it can be connected to different types of heating heads. In the specific case of the 
present application, the heating head is formed by four coils connected in series, which allows the same current circulating in each coil and, in case the same component (dimensions, shape and material) is placed in the coil, the same magnetic field is induced in it. By the control electronics the following working parameters can be set:

- Temperature setpoint, temperature to be reached on each pipe during the treatment. For the specific type of steel considered in the present study it ranges between $700{ }^{\circ} \mathrm{C}$ and 950 ${ }^{\circ} \mathrm{C}$;

- Processing time: the amount of time that the temperature must be kept on the parts. In the present application, in order to make the induction heat treatment competitive with the production goal, this time was maintained as low as possible.

The temperature is measured in real-time by an infrared punctual device calibrated according to the material emissivity. The temperature signal is used by the generator as feedback and security signal during the heat treatment, which in case can be stopped if the temperature on the monitored part is not reached after a certain time.

\subsection{The micro-indentation test}

The first type of mechanical test carried out on the specimens was a micro-indentation test performed by the Anthon-Parr instrumented hardness station available at the Mech-LAB of the Department of Mechanical, Energy and Management Engineering at University of Calabria. This specific equipment shown in Fig. 1a) is formed by four modules: the nano-indenter, the microindenter, the optical profilometer and the optical microscope. For the present application only the micro-indenter and the optical microscope modules were used. The specimen in mounted on a $x y$ motorized translation stage, which allows to choose the location of the indentations and to program any geometric pattern of tests.

The specimens analyzed by this type of test consist in a piece of pipe (full cylinder in the case of original material) whose surface was properly prepared in order to achieve high precision geometrical properties, which allow good accuracy and repeatability when the micro-indentation test is performed. In particular, after obtaining an axial section, the specimen is initially mounted in a cylindrical thermoset resin by the Struers mounting press model CitoPress-1 (Fig. 1b). In the way the exposed surface allows to test possible mechanical properties' gradients along both radial and axial direction. Figure 1c) shows five mounted specimens, where the first on the left is the full cylinder representing the original materials (no mechanical or thermal treatments), and the others are the pipe shaped specimens with a code to identify the different technological processes applied on each of them.

Once mounted, the specimens were grinded and polished, in order to achieve the required surface roughness necessary to attain accurate results by an instrumented micro-indentation test, characterized by quite small penetration depth (few micrometers). These final operations were applied by the Struers grinding and polishing equipment model Tegramin-25 (Fig. 1d), by which a grinding/polishing protocol for that specific steel was applied. It is based on five steps, whose main features are schematically reported in Fig. 1e), where under the image of the disc shaped abrasive tool are indicated: the type of tool (SiC foil, disc or cloth); the fineness of the abrasive surface (grit number for the foil, suspension particle size for disc and clothes); the processing time. For the sake of brevity, other parameters (e.g. force applied, amount of lubricant, type of abrasive suspension, relative direction and rotation speeds of tool and specimen) set during the surface treatment are not reported. 


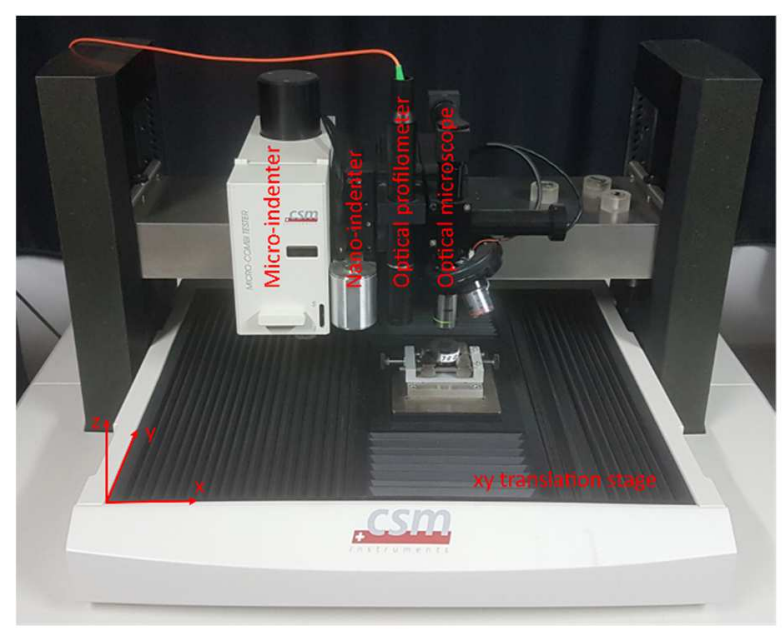

a)

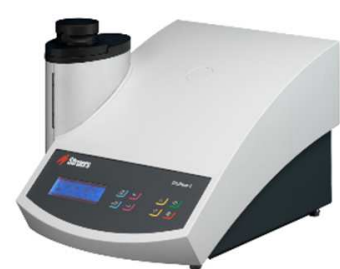

b)

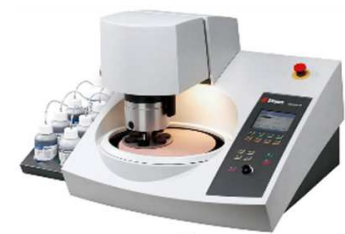

d)

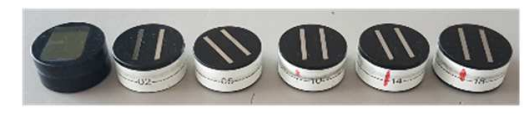

c)

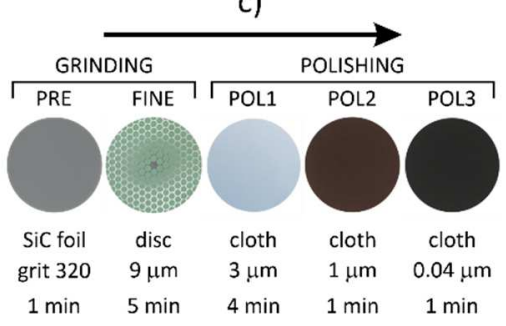

e)

Figure 1. Equipment to perform instrumented micro-hardness test: a) Anton-Parr micro- and nano- indentation station; b) mounting machine Struers, model CitoPress-1; c) mounted specimens; d) grinding/polishing machine Struers, model Tegramin-25; e) abrasive tools and main process parameters for surface treatment.

After a series of tests, a protocol to execute the instrumented micro-indentation test was established. This type of test consists in measuring the loading and unloading portions of the load/displacement curve when a specific indenter is applied on the surface under investigation. Generally, the test is carried out in load control (Fig. 2a), with fixed increasing and decreasing speeds $\left(v_{i}\right.$ and $\left.v_{d}\right)$ and a pause in between $\left(t_{p}\right)$. The consequent displacements are measured by a proper sensor mounted on the head (Fig. 2b), and the final load/displacement is obtained by eliminating the temporal coordinate (Fig $2 \mathrm{c}$ ). The choice of the maximum load $F_{\max }$ is crucial due to the nonlinearity of the whole experiment, whereas the resulting maximum displacement $\delta_{\max }$ is simply measured by the equipment. Another parameter to be chosen is the indenter type. The most common are spheres, corner cube, Vickers and Berkovich. In the present study, the parameters for $v_{i}, v_{d}$ and $t_{p}$ were chosen in the usual ranges used for steels, that are $50 \mathrm{mN} / \mathrm{s}, 50 \mathrm{mN} / \mathrm{s}$ and $10 \mathrm{~s}$, respectively. The selected indenter was the Vickers, and $F_{\max }$ was fixed to $1.5 \mathrm{~N}$. The value of $1.5 \mathrm{~N}$ represents the tradeoff between two opposite needs: the higher the more accurate are the measurements of load and displacement; the lower the smaller is the indent dimension on the surface, which implies a more reliable retrieval of the properties' gradients.

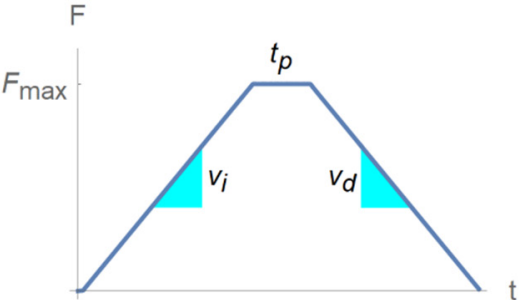

a)

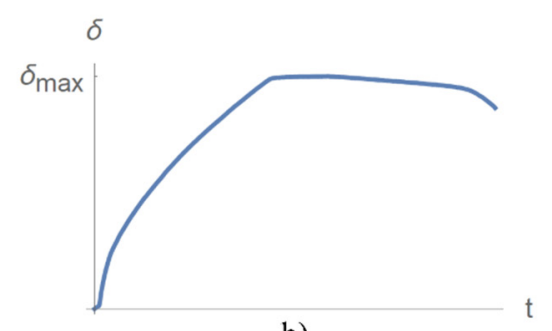

b)

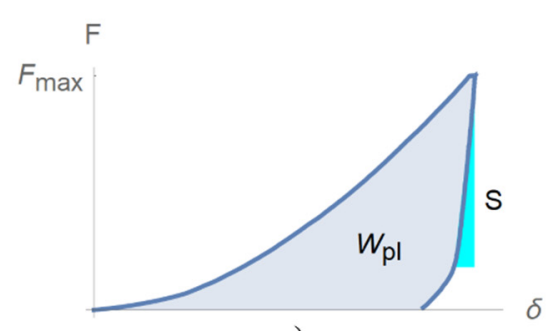

c)

Figure 2. Experimental results obtained by an instrumented micro-indentation test: a) load vs time; b) displacement vs time; c) overall load/displacement curve with emphasized the two material's parameters $W_{\mathrm{pl}}$ (plastic work) and $S$ (slope of the unloading curve used for Young's modulus evaluation).

The mechanical properties attainable from this type of test in its standard implementation are:

- The Vickers hardness $H_{\mathrm{it}}$, equal to the $F_{\max }$ divided by the surface area of the resulting indentation;

- The plastic work $W_{\mathrm{pl}}$, equal to the area included between the loading and unloading curves;

- The Young's modulus $E$, related to the initial slope of the unloading curve $S$. 
Considering that Young's modulus is not significantly affected from thermal and mechanical treatments, the properties chosen to compare the effects of the localized heat treatment on the material performance were $W_{\mathrm{pl}}$ and $H_{\mathrm{it}}$, which provide an estimation of the induced ductility and strength variations, respectively.

\subsection{The tensile test}

When possible, the use of hardness test is particularly convenient for the mechanical characterization of a material. In fact, the highly localized volume of the material involved in the test often allows to avoid the preparation of specific specimen according to standard protocols, with the consequent advantages both to evaluate possible mechanical properties' gradients and to apply the test directly on prototypes or even real components. On the other hand, the properties obtained by an instrumented micro-indentation test cannot be easily applied in the design procedures, which generally are based on the mechanical properties determined by a tensile test (i.e. yield strength, tensile strength, plastic flow parameters, tensile ductility).

In this scenario, the correlation between the properties measured by the two types of test would be particularly useful, with the aim to attain parameters meaningful for design issues (i.e. the ones measured by the tensile test) by an easier, cheaper and less invasive experimental procedure (i.e. instrumented micro-indentation test). Unfortunately, the determination of this sort of correlation is strongly material-dependent, therefore it is not possible to define general relations working for any material, whereas an ad hoc study for a specific material (or class of materials) has to be carried out.

With this goal, a rectilinear tube-shaped specimen was analyzed by a tensile test according to the ASTM standard E8/E8M-16a. Due to the localized heat treatment applied to the specimen, the mechanical response of the specimen resulted to be heterogeneous, hence it was not possible to assume the typical strain field occurring on a homogeneous specimen subjected to a uniaxial stress state. As commented in the section reporting the results of the indentation tests, no significant radial or circumferential gradients were observed in terms of material properties. Hence the only spatial variable affecting the mechanical response is the axial direction. In this hypothesis, the variation of the mechanical properties can be measured by evaluating the longitudinal strain gradients induced by the uniaxial stress state, which instead, for a homogeneous material, would have induced a uniform distribution of this strain component.

The evaluation of the values necessary to retrieve the longitudinal strain gradient was accomplished by means of DIC methods. A schematic of the experimental setup is shown in Fig. 3 . The tensile test was applied by a universal testing machine (MTS, model Criterion 45) on a tubular specimen. According to ASTM standard prescriptions, two snug-fitting metal plugs were inserted in the ends of the specimen, to permit the machine jaws to properly grip the specimen. The test was carried out in displacement control, by applying a load speed to the crosshead equal to $0.25 \mathrm{~mm} / \mathrm{min}$. Voltages proportional to load and displacement were used as reference signals to synchronize the images acquired by the camera Prosilica model ATV-GT2450 (resolution 2448 pixel x 2050 pixel, pixel dimension $3.45 \mu \mathrm{m} \times 3.45 \mu \mathrm{m}$, maximum frame rate $15 \mathrm{~Hz}$ ). The image illumination was optimized by two diode light sources placed symmetrically around the camera. All the signals (voltages and images) were acquired by a workstation interfaced with all devices by the data acquisition system ISI-SYS model DAQ-STD-8D. 


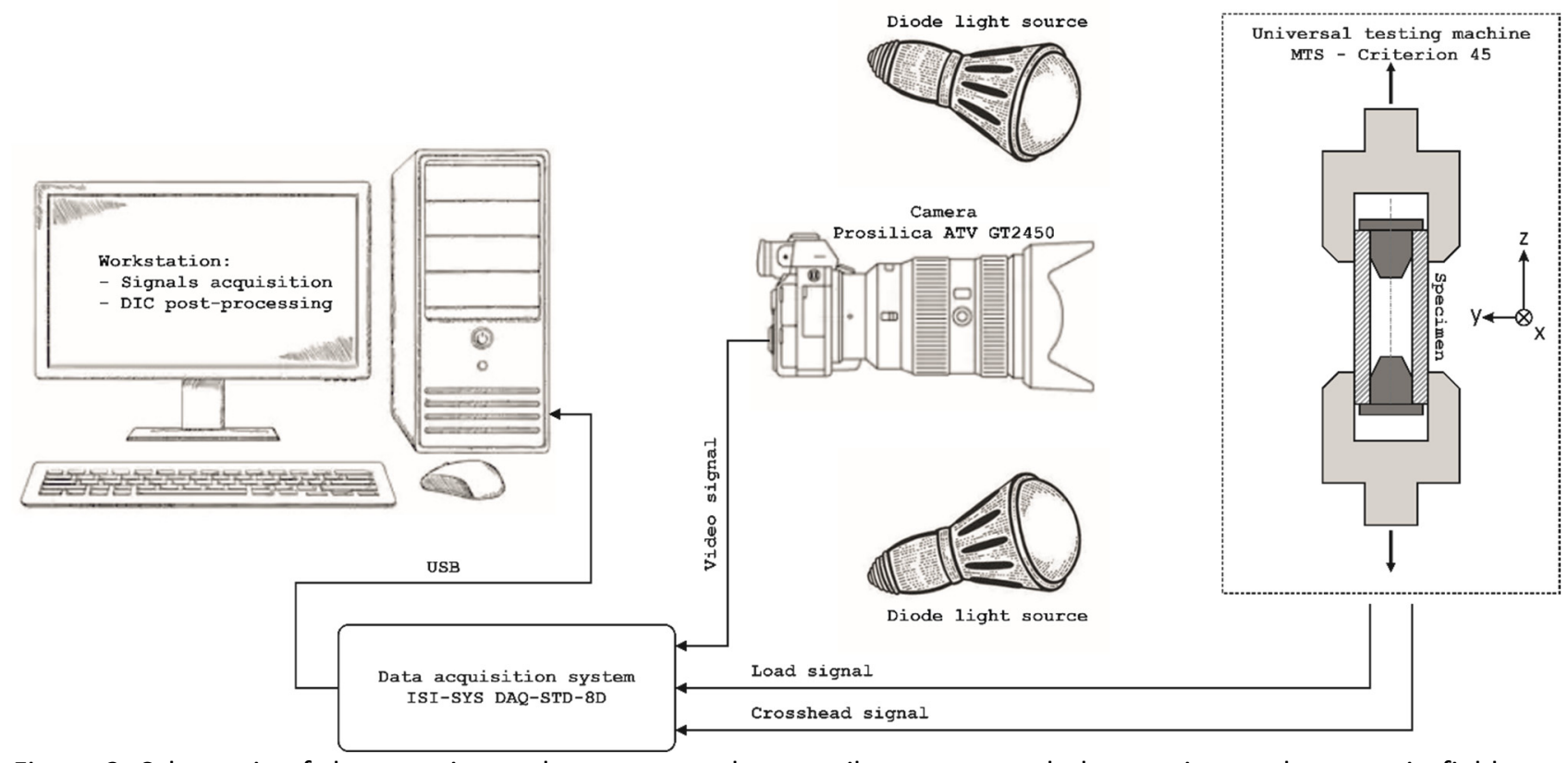

Figure 3. Schematic of the experimental setup to apply a tensile test on a tubular specimen whose strain field was measured by the full-field optical technique based on DIC methods.

Figure 4 shows some images used in the DIC analysis. In particular, Fig. 4a) shows the image used for the metric calibration, while Figs. $4 b$ ) and 4c) depict the first and the last image acquired during the tensile test. Assuming that the only spatial coordinate affecting the mechanical response is the axial direction ( $z$ axis), 11 zones (the alternated yellow and red rectangles in Fig. 4, where the material properties due to the reduced extension can be assumed constant) were defined and analyzed separately. The dimensions of each zone are $2 \mathrm{~mm} \times 1 \mathrm{~mm}$ along $\mathrm{x}$ - and z-direction, respectively. The stress state existing in the whole specimen is uniaxial, hence it does not change in the highlighted zones, whereas the strain state changes accordingly to the mechanical properties.

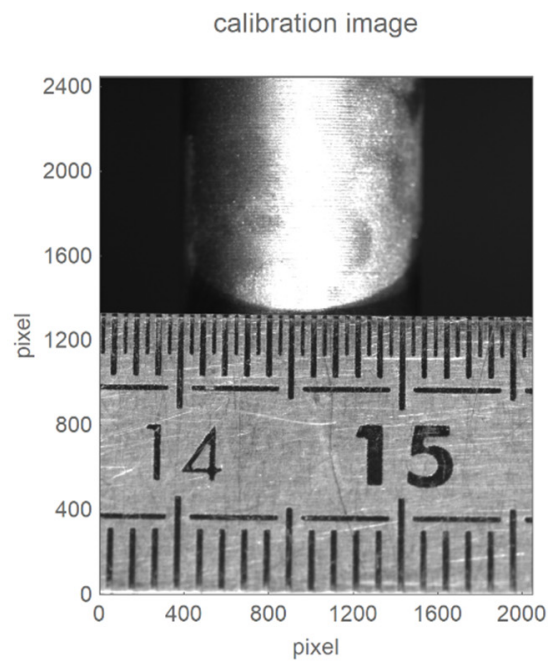

a)

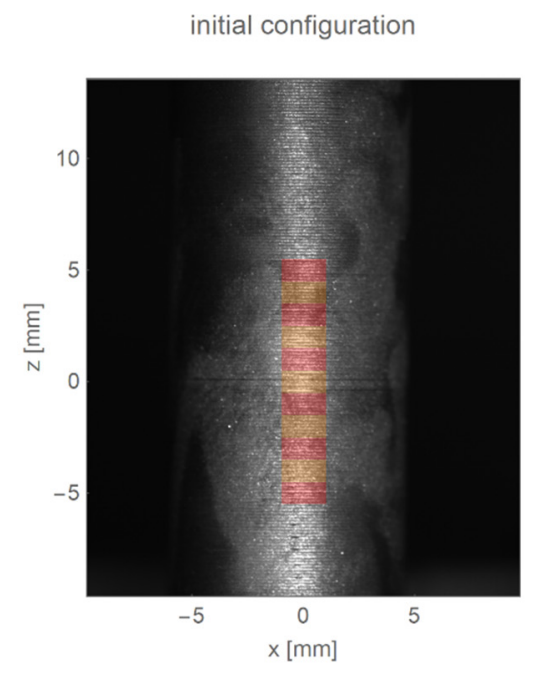

b)

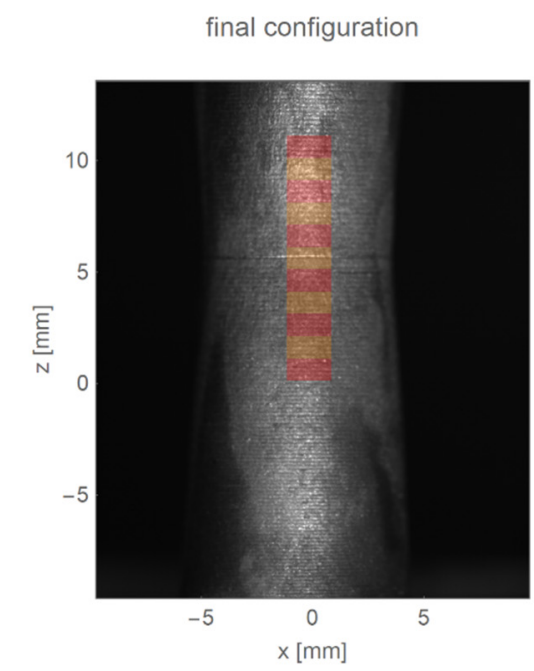

c)

Figure 4. Some of the images used for DIC analysis: a) metric calibration; b) initial and c) final configurations of the tensile test. In the red and yellow rectangles, the mechanical response was assumed constant and studied separately, in order to quantify the material properties' gradients. 


\subsection{The specimens}

Different types of specimens were analyzed with the aim of evaluating the impact on the mechanical properties of the different process parameters of the localized heat treatment, and the effectiveness of the proposed testing methods.

Table 1 reports the main feature of the investigated specimens. The base material was initially tested (specimen \#0), which consists in a full bar with a $15 \mathrm{~mm}$ outer diameter. Specimen \#1 is lathe machined tube with inner and outer diameters equal to 7 and $11 \mathrm{~mm}$, respectively. All the other specimens were subjected to heat treatments after being machined. In particular, specimen \#2 was annealed in order to evaluate the maximum ductility attainable form the material, whereas all the others (from \#3 to \#8) were treated by the localized induction heating with different process parameters (temperature and time treatment) and different geometry of the pipe (inner and outer diameters).

\begin{tabular}{ccccccc} 
& \multicolumn{2}{c}{ Mechanical and heat treatments } & \multicolumn{2}{c}{ Dimensions } \\
\hline ID & type & $T \quad\left[{ }^{\circ} \mathrm{C}\right]$ & $t \quad[\mathrm{~s}]$ & $D_{\text {i }}$ & {$[\mathrm{mm}]$} & $D_{\circ}[\mathrm{mm}]$ \\
\hline$\# 0$ & None & NA & NA & - & 15.0 \\
\hline$\# 1$ & $\mathrm{M}$ & $\mathrm{NA}$ & $\mathrm{NA}$ & 7.0 & 11.0 \\
\hline$\# 2$ & $\mathrm{M}+\mathrm{A}$ & 935 & 468 & 7.0 & 11.0 \\
\hline$\# 3$ & $\mathrm{M}+\mathrm{LI}$ & 700 & 10 & 7.0 & 11.0 \\
\hline$\# 4$ & $\mathrm{M}+\mathrm{LI}$ & 800 & 5 & 7.0 & 11.0 \\
\hline$\# 5$ & $\mathrm{M}+\mathrm{LI}$ & 850 & 1 & 7.0 & 11.0 \\
\hline$\# 6$ & $\mathrm{M}+\mathrm{LI}$ & 780 & 1 & 4.0 & 8.0 \\
\hline$\# 7$ & $\mathrm{M}+\mathrm{LI}$ & 850 & 1 & 5.0 & 11.0 \\
\hline$\# 8$ & $\mathrm{M}+\mathrm{LI}$ & 850 & 6 & 9.5 & 14.0 \\
\hline
\end{tabular}

Table 1. Specimens and (mechanical and heat) treatments applied on them. M: machined, A: annealed, LI: localized induction heating.

\section{Experimental results}

Before starting to investigate the effect induced on the material's mechanical response from the localized induction heat treatment, three conditions were analyzed, in order to establish some reference values for the mechanical properties. Hence, initially specimens \#0, \#1 and \#2 were tested by micro-indentation tests, and the reference values for the $W_{\mathrm{pl}}$ and $H_{\text {it }}$ were evaluated. Subsequently, the same properties were measured on specimens from \#3 to \#8 with the aim of identifying the effects of the localized induction heating. Several tests were also carried out to evaluate possible spatial gradients of the mechanical properties. Finally, a uniaxial test was performed on the specimen \#5 in order to evaluate the correlation between the properties obtained by the two types of experimental approaches.

\subsection{Reference specimens subjected to instrumented micro-indentation test}

Specimens \#0, \#1, and \#2 were initially tested to evaluate reference values of the mechanical parameter and to understand the potential existence of their spatial gradients. The geometric axial symmetric shape of the specimen and the type of (mechanical and thermal) treatments applied to the material made reasonable to exclude circumferential gradients, whereas the axial and radial directions were considered possible potential spatial variables for these gradients. In this hypothesis, different areas were investigated by performing the micro-indentation tests at several 
points of known coordinates. In particular, the three different areas highlighted by red boxes in Fig. $5 a)$ were considered for the base materials (specimen \#0), while the two red boxes in Fig. $5 \mathrm{~b}$ ) were analyzed for the specimen \#1 and \#2. In all the cases no significant spatial gradients were observed.

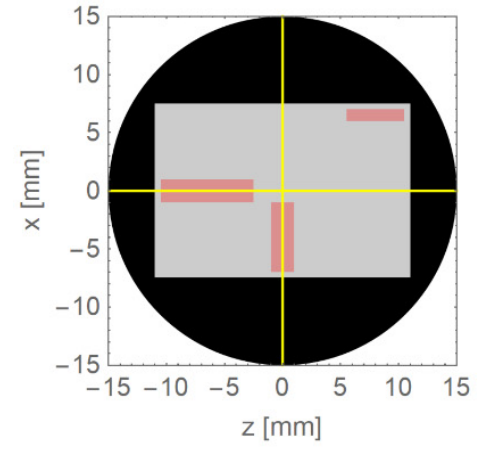

a)

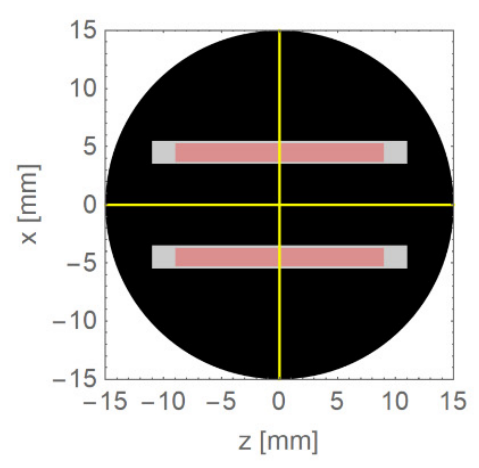

b)

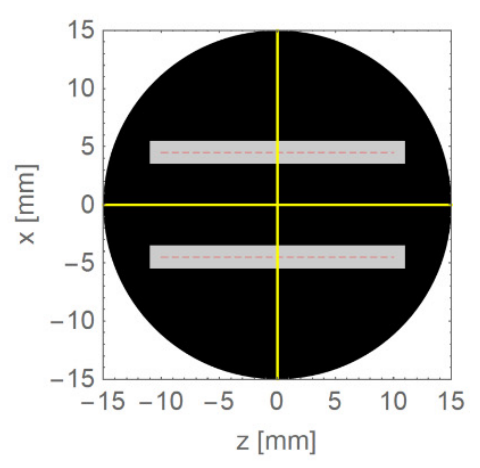

c)

Figure 5. Top view of specimens (gray area) mounted in the resin (black area) and the area where the micro-indentation tests were performed (red area): a) base material; b) treated material to identify radial and axial gradients; treated material to identify the only axial gradient.

The material properties obtained for these three reference specimens by the instrumented microindentation tests are shown in Fig. 6 . In particular, Figs. 6a) and b) shows the Vickers hardness $\left(H_{\text {it }}\right)$ and the plastic work $\left(W_{\mathrm{pl}}\right)$ for the base material (specimen $\left.\# 0\right)$, Figs. $6 \mathrm{c}$ ) and d) for the lathe machined material (specimen \#1), and Figs. 6e) and f) for the machined and annealed material (specimen \#2). The red continuous lines represent the mean value $\mu$, the dashed lines the double of the standard deviation $\sigma$ added and subtracted from the mean value. Several tests were carried out on the aforementioned highlighted areas, by performing three matrices of tests - Fig. 6a) - for the base material ( $11 \times 11,17 \times 11,21 \times 25$, total 833 tests) and the two same matrices - Fig. 6b) - on the other two specimens $(2 \times 19 \times 17$, total 646 tests). Due to the highly localized material volume involved in the single test, some results falling quite far from the average value were discarded. By calculating the average values for $H_{\mathrm{it}}$ and $W_{\mathrm{pl}}$, it is possible to conclude that the machining does not imply substantial changes in the mechanical response, while the annealing modifies deeply the material, by significantly increasing its ductility and decreasing its hardness. Table 2 shows the statistical parameters $\mu$ and $\sigma$ of $H_{\text {it }}$ and $W_{\mathrm{pl}}$ for the three reference specimens. The mean values of the specimen \#1 were assumed as reference values to compare and quantify the mechanical properties obtained on the induction heat-treated materials, reported in the following section. 


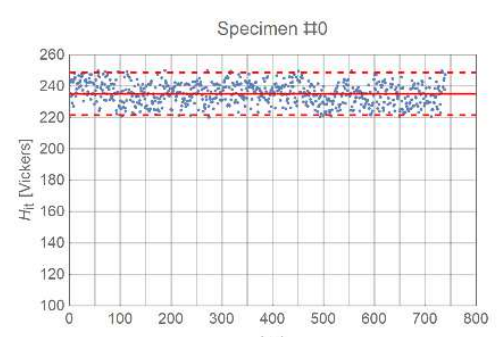

a)

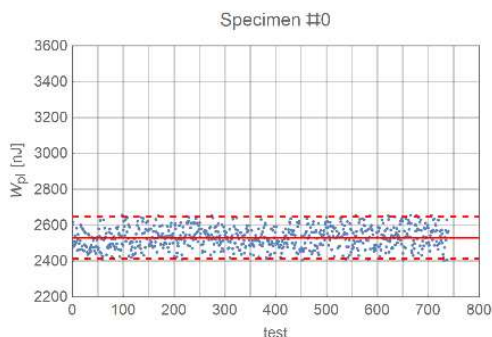

b)

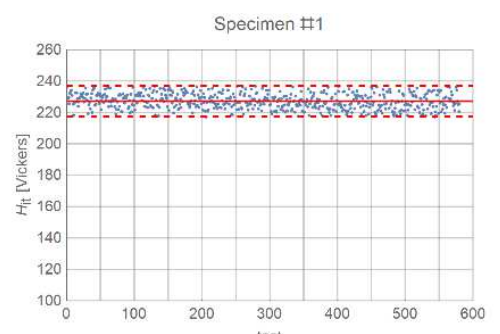

c)

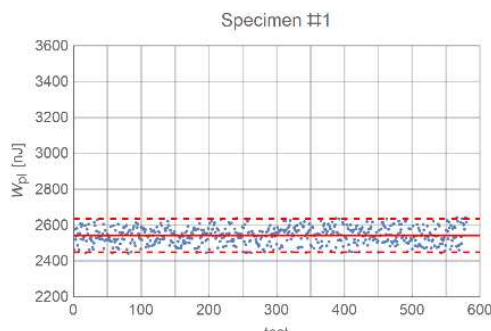

d)

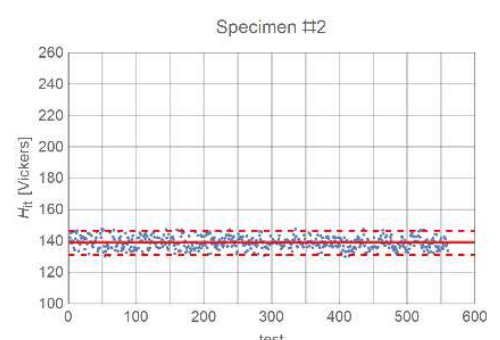

e)

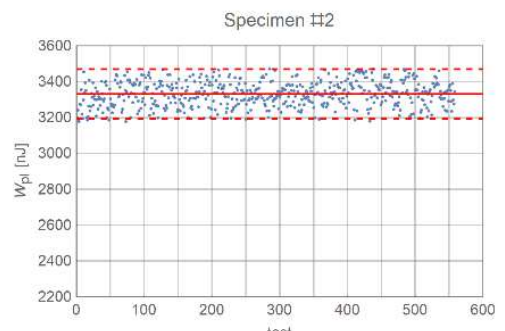

f)

Figure 6. Vickers hardness $\left(H_{\mathrm{it}}\right)$ and plastic work $\left(W_{\mathrm{pl}}\right)$ obtained for the three reference specimens: a) and b) specimen $\# 0$, the base material; c) and d) specimen \#1, lathe machined material; e) and f) specimen \#2, machined and annealed material.

\begin{tabular}{ccccc} 
& \multicolumn{2}{c}{ Hardness $\left(H_{\mathrm{it}}\right)[$ Vickers] } & \multicolumn{2}{c}{ Plastic work $\left(W_{\mathrm{pl}}\right)[\mathrm{nJ}]$} \\
\hline Specimen & $\mu$ & $\sigma$ & $\mu$ & $\sigma$ \\
\hline$\# 0$ & 235.1 & 6.8 & 2530 & 59 \\
\hline$\# 1$ & 227.2 & 4.9 & 2543 & 47 \\
\hline$\# 2$ & 138.9 & 3.8 & 3331 & 69 \\
\hline
\end{tabular}

Table 2. Mean value $\mu$ and standard deviation $\sigma$ of $H_{\text {it }}$ and $W_{\mathrm{pl}}$ for the three reference specimens.

\subsection{Localized induction heat treated specimens subjected to instrumented micro-indentation test} The next three specimens $(\# 3, \# 4, \# 5)$ tested by the micro-indenter are characterized by the same size $\left(D_{\mathrm{i}}=7 \mathrm{~mm}, D_{0}=11 \mathrm{~mm}\right)$ but by different process parameters ( $T$ and $\left.t\right)$. The aim was to understand if by different combinations of processing temperature/time could generate similar mechanical properties, therefore lower process temperatures were applied for a longer time, in order to provide to the less energetic configurations more time to re-arrange the crystalline structures. Similarly, for these specimens the areas shown in Fig. 5b) were tested to identify potential spatial gradients of the properties. In this case, the axial direction ( $x$-axis) showed clearly a gradient, whereas along the radial direction ( $y$-axis) no significant mechanical properties' variations were observed.

Figure 7 shows the results for this group of specimens, in this case the graphs are displayed according to the local abscissa $x$ (spanning an interval of $20 \mathrm{~mm}$ length), while the $y$ information is not considered. The continuous (mean value) and dashed (two times the standard deviation distance from the mean value) curves have the same meaning of the straight lines of Fig. 6 . The gray bands in the graphs emphasize minimum and maximum values obtained in the reference conditions (Table 2, specimens \#1 and \#2) for the $H_{\text {it }}$ and $W_{\text {pl }}$.

The shape of the gradient is quite clear, which consists in a single concavity variation with a maximum occurring around the center of the warming coil (having a length of $40 \mathrm{~mm}$ ). The identification of the center is not straightforward due to both the uncertainty arising during the 
position of the pieces of pipe inside the induction machine, and the machining of the pipes themselves necessary to obtain the specimen.

The results of Fig. 7 show visibly that the time of application of the heat is not particularly relevant, whereas what truly impacts the mechanical properties is the processing temperature, with a clear increase (decrease) of ductility (hardness) with the temperature. Hence, if the localized induction treatment is performed on a pipe with the aim of increasing the formability of the portion to be subjected to high plastic deformations, a quite short process (just $1 \mathrm{~s}$ ) applied at $850{ }^{\circ} \mathrm{C}$ implies a ductility not far from the level attainable by the annealing process, which instead requires a $468 \mathrm{~s}$ treatment. In fact, in this case the maximum value for $W_{\mathrm{pl}}$ is equal to $3149 \mathrm{~nJ}$, not far from $3331 \mathrm{~nJ}$ obtained by the conventional annealing process.

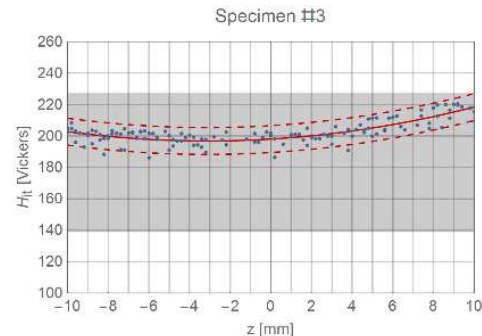

a)

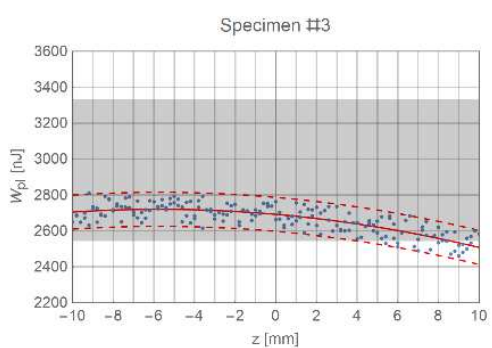

b)

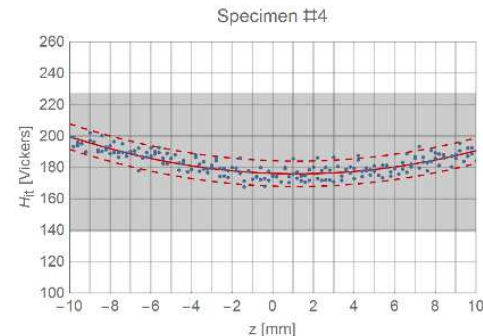

c)

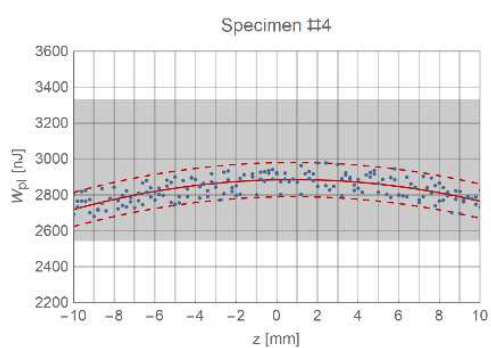

d)

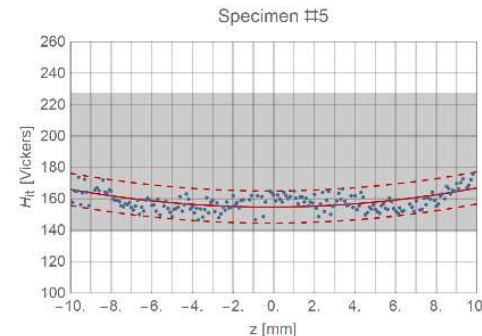

e)

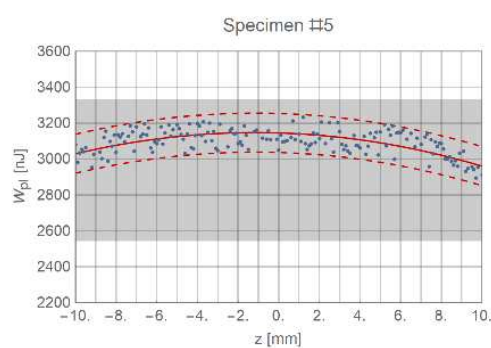

f)

Figure 7. Vickers hardness $\left(H_{\mathrm{it}}\right)$ and plastic work $\left(W_{\mathrm{pl}}\right)$ obtained for the second group of three specimens characterized by same geometrical dimensions but different processing temperature and time: a) and b) specimen \#3; c) and d) specimen \#4; e) and f) specimen \#5. The gray bands in the graphs emphasize minimum and maximum values obtained in the reference conditions (Table 2, specimens \#1 and \#2) for the $H_{\mathrm{it}}$ and $W_{\mathrm{pl}}$.

Subsequently, another group of three specimens was tested $(\# 6, \# 7, \# 8)$ with the aim of evaluating the combined effects of the process parameters ( $T$ and $t$ ) and pipe sizes $\left(D_{\mathrm{i}}\right.$ and $D_{0}$ ). Similarly, for this group of specimens the possibility of gradients formation of mechanical properties was evaluated by performing a matrix of tests as shown in Fig. 5b). Again, only the axial gradients were observed, which suggested to carry out the other tests just along the line as shown in Fig. 5c), by decreasing the step between two consecutive indentations with the aim to increase the spatial resolution used to retrieve the axial gradients.

The results are shown in Fig. 8. By comparing specimens \#6 and \#7, it is possible to conclude that regardless the different dimensions of the two specimens the temperature is still the dominant parameter. But when the overall dimension of the specimen grows significantly, as in the case of specimen \#8, the size starts being an influencing parameter. In fact, the comparison of the specimens \#7 and \#8 shows how the increase (decrease) of ductility (hardness) obtained for the bigger specimen (\#8) is lower, even if the process is applied at the same temperature $\left(850^{\circ} \mathrm{C}\right)$ for a much longer time ( $6 \mathrm{~s}$ instead of $1 \mathrm{~s}$ ). In addition, it is worth mentioning that specimen \#8 has not only bigger diameters, but is also longer, in fact the investigated length is $30 \mathrm{~mm}$ instead of $20 \mathrm{~mm}$, which required to break the specimen into two pieces due to the limitations of the mounting system 
used for the specimens. The ends of the two facing surfaces had two be machined and some local alteration occurred, hence experimental data are missing over a length of about $5 \mathrm{~mm}$.

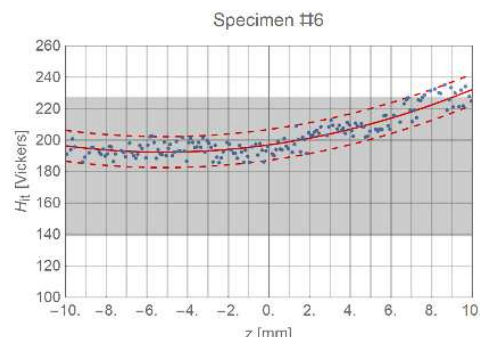

a)

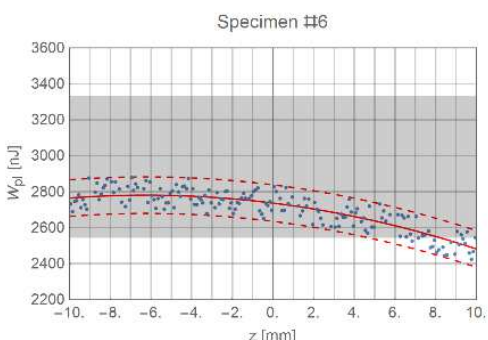

b)

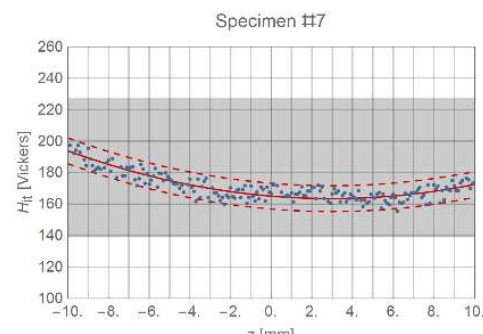

c)

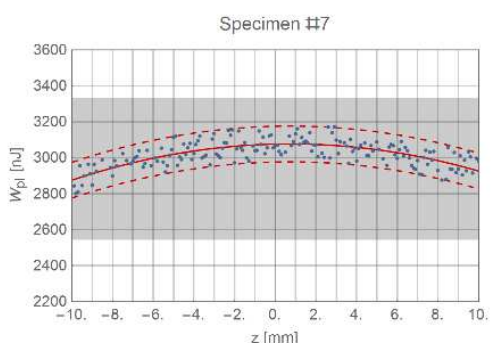

d)

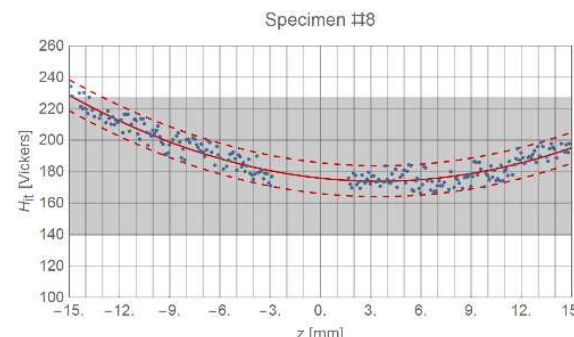

e)

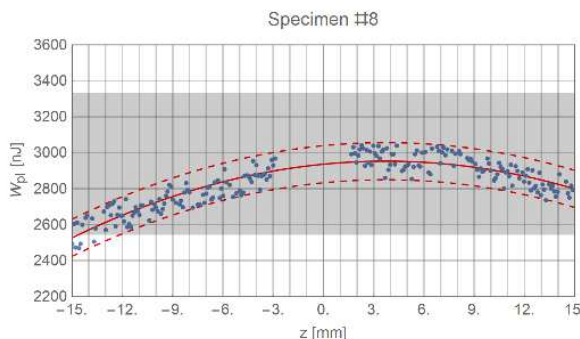

f)

Figure 8. Vickers hardness $\left(H_{\mathrm{it}}\right)$ and plastic work $\left(W_{\mathrm{pl}}\right)$ obtained for the third group of three specimens characterized by different geometrical dimensions and processing parameters: a) and b) specimen \#6; c) and d) specimen \#7; e) and f) specimen \#8. The gray bands in the graphs emphasize minimum and maximum values obtained in the reference conditions (Table 2 , specimens \#1 and \#2) for the $H_{\text {it }}$ and $W_{\text {pl. }}$.

\subsection{Specimen subjected to tensile test and correlation with micro-indentation test}

Specimen \#5 was chosen as a candidate to be tested by a tensile test instrumented by DIC equipment for the elongation measurement, according to the procedure described in section 2.3, and its data be subsequently correlated with those obtained by the micro-indentation test. In particular, a pipe shaped specimen was fixed in the universal testing machine jaws by means of two snug-fitting metal plugs as shown in Fig. 3. By an internal trigger signal properly generated by the experimental apparatus, the applied load, the crosshead displacement and the image of the specimen at a specific time were saved. The trigger signal was generated every $10 \mu \mathrm{m}$ of crosshead displacement or $250 \mathrm{~ms}$, whichever event occurs first. The analysis of the images by correlation algorithms allowed to evaluate the local normal strain in the 11 areas highlighted in Fig. 4, whereas the local stress can be assumed uniform until the onset of necking, which implies a highly localized overload of the specimen occurring in the weakest section and makes no longer valid the assumption of uniform stress and strain. By the local true stress $\sigma$ and true strain $\varepsilon$ values, calculated by the following equations:

$$
\begin{aligned}
& \sigma=\frac{P}{A_{0}}\left(1+\frac{\partial w}{\partial z}\right) \\
& \varepsilon=\log \left(1+\frac{\partial w}{\partial z}\right)^{\prime}
\end{aligned}
$$

the stress/strain curves shown in Fig. 9 were evaluated at the different abscissa $z$. In eqs. (1) $P$ is the applied load, $A_{0}$ the initial cross section, $w$ the displacement component along $z$ direction, and its derivative with respect of $z$ represents the nominal (or engineering) deformation used to calculate the true values. Figure 9 clearly shows how the ductility increases in the center of the specimen 
(around $z=0$ ), where the curves extended up to quite higher strain levels. These curves cannot be considered the complete mechanical behavior up to the failure of the material, because the fracture of the specimen occurred in the that section where the necking started due to the stress concentration. From that instant, the stress in no longer uniform, and the fracture happening in this section does not allow to evaluate the evolution of the different stress/strain response due to the localized heat-treatment applied to the material.
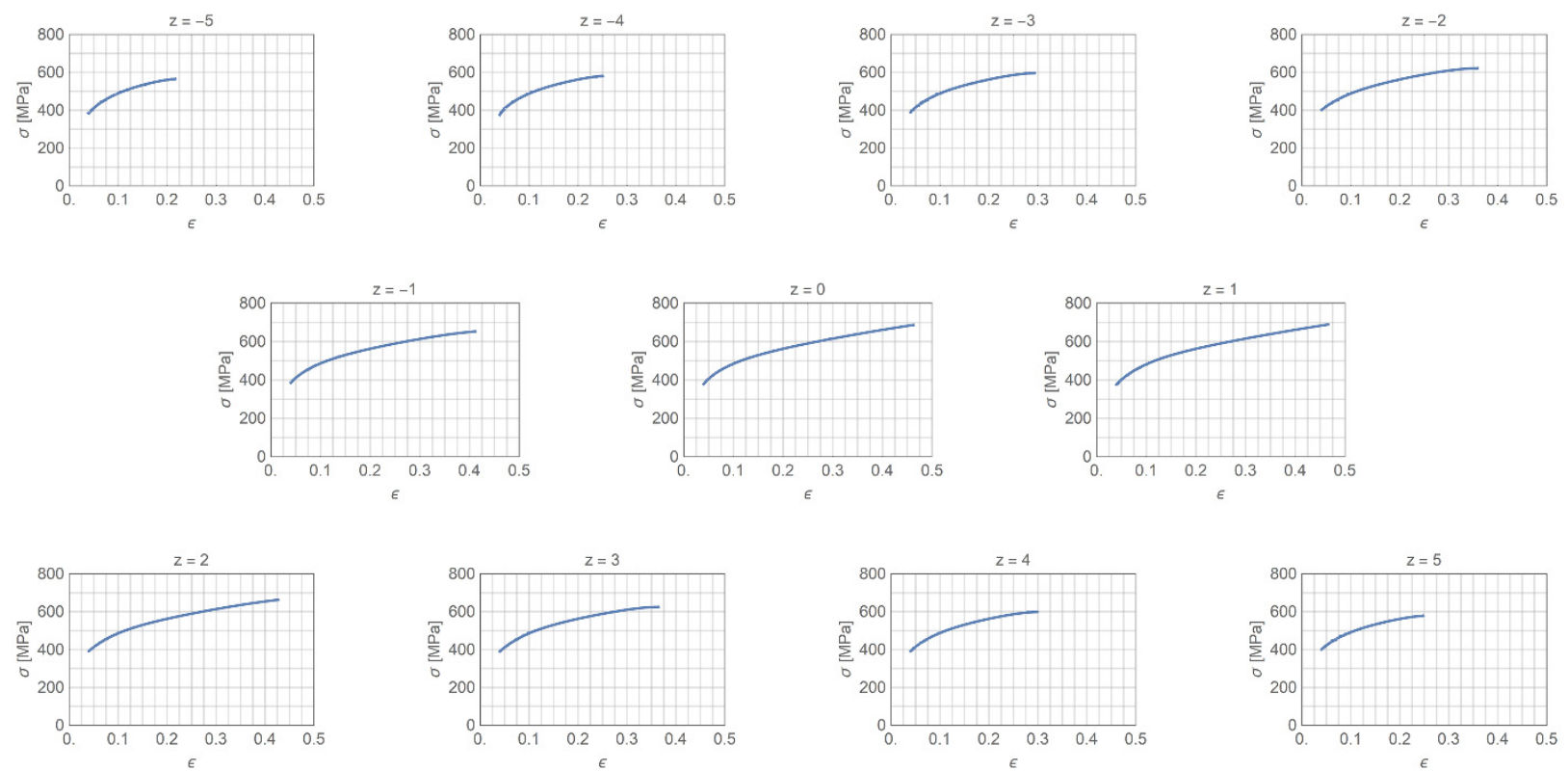

Figure 9. True stress / true strain curves variation with the axial direction of the specimen \#5 obtained by combining the load, measured by the load cell mounted onboard the machine, and the displacement field, measured by DIC.

Nevertheless, some further considerations can be done by analyzing the data of Fig. 9. In fact, according to theory of plasticity [29], the condition revealing the necking onset is given by the following condition:

$\frac{\partial \sigma}{\partial \varepsilon}=\sigma$,

which can be easily imposed to the curves shown in Fig. 9. Figure 10 shows the plot of the functions $\partial \sigma / \partial \varepsilon$ at different abscissas $z$, whereas the red points represent the coordinates $\left(\varepsilon_{N}, \sigma_{N}\right)$ which satisfy the eq. (2), that is the onset of necking. These parameters $\left(\varepsilon_{N}, \sigma_{N}\right)$ can be considered material's properties and they can be put in a graph in function of the abscissa $z$, as shown in Fig. 11, where the gradients of both $\varepsilon_{N}(z)$ in Fig. 11a) and $\sigma_{N}(z)$ in Fig. 11b) are reported. It is possible to notice the same trend of the parameter $W_{\mathrm{pl}}$, with its maximum value occurring in the midplane.

By using the fitting curves of the parameters $\varepsilon_{N}(z), \sigma_{N}(z)$ and $W_{p l}(z)$, an empirical correlation law can be easily obtained. Before identifying this law, it is necessary to "align" the different curves, that means to translate horizontally them in order to set the same abscissa $z$ of the maximum values. The coincidence of the maxima is certainly a reasonable assumption, considering the difficulties in practical identification of such a point, and the fact that the material characterized by the highest ductility (maximum $W_{\mathrm{pl}}$ ) should also show the latest necking onset condition (maximum $\varepsilon_{N}$ and $\sigma_{N}$ ). 

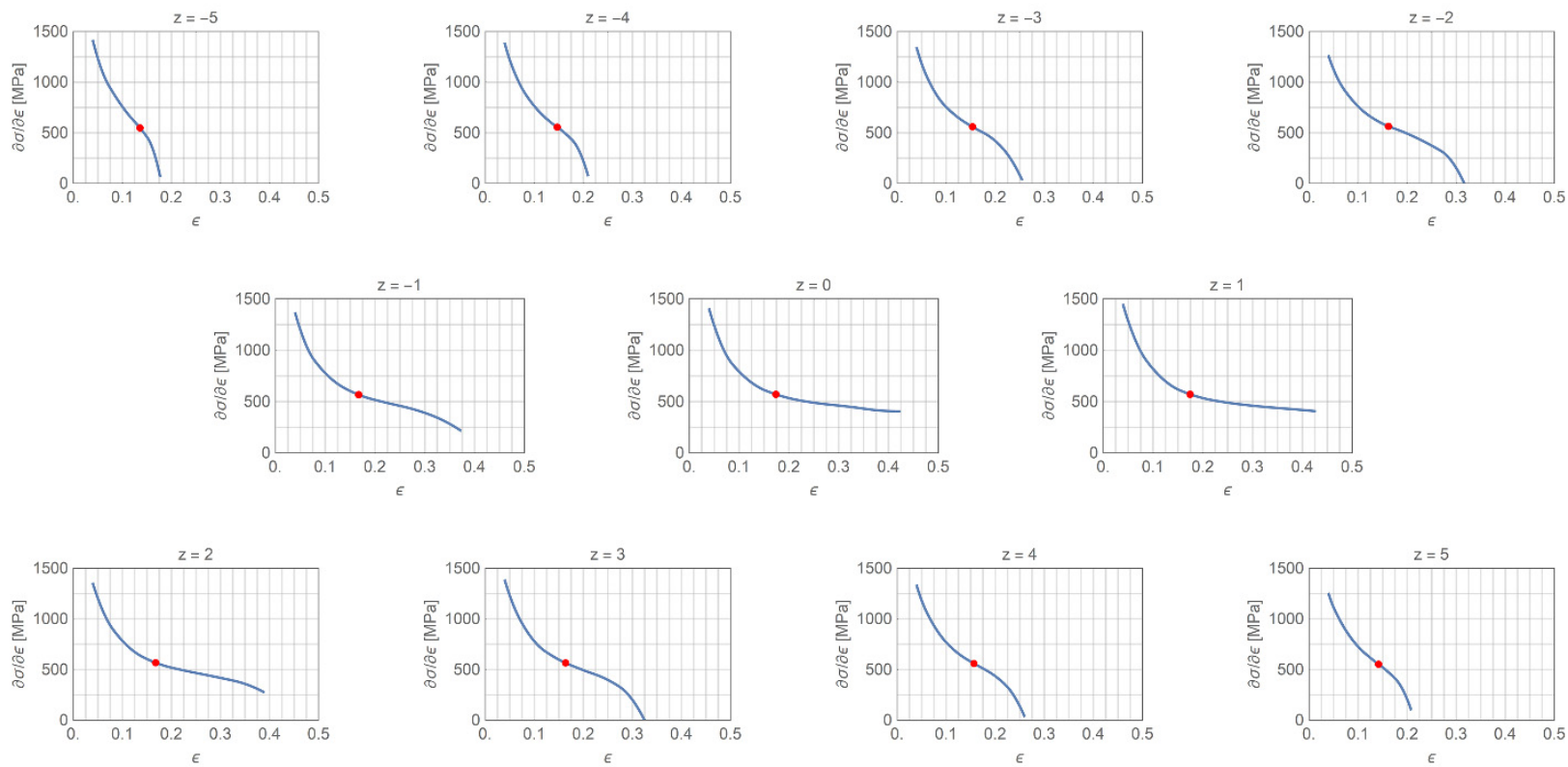

Figure 10. Derivatives of stress/strain curves along the axial direction and the points (red dot) representing the onset of the necking.

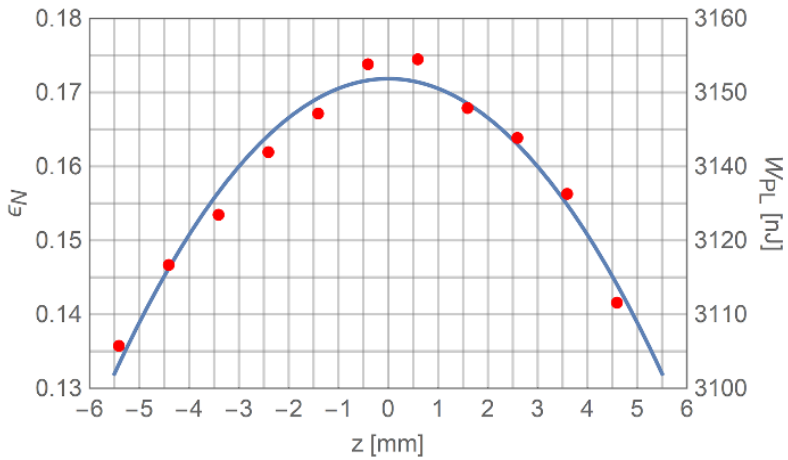

a)

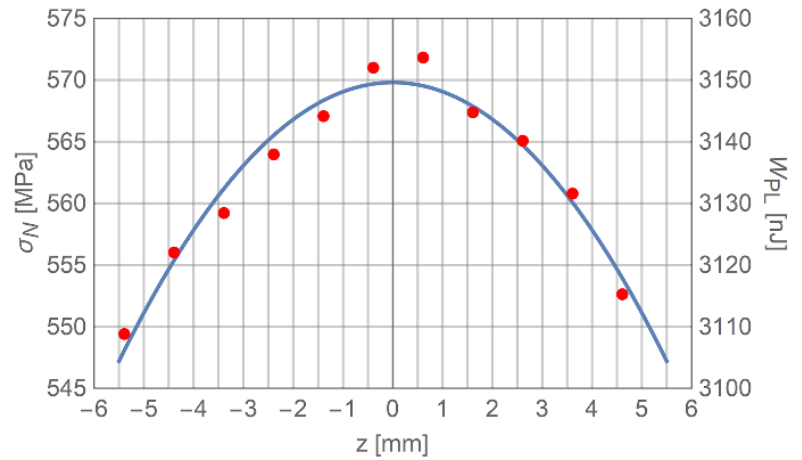

b)

Figure 11. (a) strain $\varepsilon_{\mathrm{N}}$ and (b) stress $\sigma_{\mathrm{N}}$ gradients at the necking onset, and correlation with the plastic work $W_{\mathrm{pl}}$.

Subsequently, by matching the second-degree polynomials, the following two equations can be obtained:

$\varepsilon_{N}=0.8531 \times 10^{-3} W_{\mathrm{pl}}-2.515$
$\sigma_{N}=0.4834 W_{\mathrm{pl}}-952.8$

which provide the empirical relation existing between the mechanical properties obtained by a tensile test $\left(\varepsilon_{N}, \sigma_{N}\right)$ and an instrumented micro-indentation test $\left(W_{\mathrm{pl}}\right)$. Obviously, these correlations do not hold in the whole range of the involved properties, but they are quite consistent on the considered intervals and it is reasonable to slightly extrapolate these equations out of the studied range. 


\section{Discussion and conclusions}

The study described in the present paper aims to identify experimental tools capable of evaluating the mechanical response of materials subjected to heat treatment, implying significant modifications and potential gradients of the properties of the superficial material - i.e. induction heating.

For this purpose, the instrumented micro-indentation test resulted as quick, reliable and economical, and two quantities - i.e. the Vickers hardness $H_{\text {it }}$ and plastic work $W_{\mathrm{pl}}$ - achieved through the simple post-processing of the loading/unloading curves, proved to be a good comparative estimation of strength and ductility when a specific material subjected to different treatments is analyzed. Due to the complex stress state induced by this type of test, mechanical properties directly usable for design purposes and typical obtained by a standard tensile test - i.e. yield and tensile strength, ductility and plastic flow parameters - cannot be measured straightforwardly. As such, the authors demonstrated how, for a fixed material, simple empirical mathematical laws can be estimated by correlating the experimental results of the microindentation tests with the mechanical properties measured on the same material. This is done through a standard tensile test on a material whose strain distribution is characterized by nonnegligible spatial gradients retrieved by a full-field optical method - i.e. Digital Image Correlation, DIC.

A comparison of the results attained through these two experimental methods, demonstrate how for the analyzed material, in a limited range, the ductility (quantified as the stress or strain at the necking onset measured by the tensile test) is directly proportional to the plastic work (quantified as the area between the loading and unloading curves, measured by the micro-indentation test). If the range is extended, the correlation law (still monotonic) begins to be non-linear and can be evaluated by points or by a piecewise linear function.

The material investigated in the present study is a cold drawn bar of $11 \mathrm{SMnPb30}$ steel, characterized by good, high-speed machinability and limited weldability. Bars made from this material were used to build pipes for different hydraulic applications. A short portion (about $40 \mathrm{~mm}$ ) of the pipes machined out of the base material was subjected to an induction heat treatment by changing the two main process parameters - i.e. temperature and processing time. The effect on the pipe size was also investigated.

The experimental campaign was initially intended to determine reference values for the mechanical properties of the material in its virgin form (no any kind of heat treatment performed on it), and then again when a conventional annealing was applied to it. In the first case, the material exhibits its maximum strength and minimum ductility, with a consequent maximum hardness (227.2 Vickers) and minimum plastic work ( $2543 \mathrm{~nJ}$ ) that represents the best configuration to carry the highest load in normal working conditions. On the contrary, in the second case, the material is characterized by the minimum strength (minimum hardness, 138.9 Vickers) and maximum ductility (maximum plastic work, $3331 \mathrm{~nJ}$ ), which represents the best configuration when the material must be processed by plastic deformation - e.g. bending operations. Subsequently, after fixing the dimensions of the pipes, different combinations of processing temperature and time were applied during the induction heat treatments. Temperature resulted as the most influential parameter. In fact, the most significant increment of ductility was obtained when a process temperature of $850{ }^{\circ} \mathrm{C}$ was applied, with a maximum plastic work of $3149 \mathrm{~nJ}$, quite close to the numbers acquired during the annealing. Finally, the effect of pipe dimension was considered, and it was determined that an increase of size implied reduced effectiveness of the induction heat treatment. In all the cases, a clear gradient of the mechanical properties was observed and quantified with the adopted investigation methods. 
In conclusion, the authors demonstrated how a localized induction heat treatment can be successfully performed on pipe-shaped specimens in order to significantly increase the ductility of the material and consequently its formability. For the specific type of steel considered, an induction heat treatment performed at $850{ }^{\circ} \mathrm{C}$ applied for one second provided a ductility quite close to that attainable with a conventional annealing treatment that lasts several minutes. The process also demonstrated the existence of a clear correlation between stress and strain at the onset of the necking, measured through a conventional tensile test, and plastic work, measured by a microindentation test that can be adopted as a quick, reliable and cheap characterization method for materials processed by innovative treatments.

\section{References}

1. Novikov II (1978) Theory of Heat Treatment of Metals. Mir Publishers

2. Lozinskij MG (1969) Industrial applications of induction heating. Pergamon Press, London

3. Rudnev V, Loveless D, Cook R, Black M (2003) Handbook of Induction Heating. Marcel Dekker, New York

4. Rudnev VI, Loveless D (2014) Induction Hardening: Technology, Process Design, and Computer Modeling

5. Jászfi V, Prevedel P, Eggbauer A, et al (2019) Influence of the parameters of induction heat treatment on the mechanical properties of $50 \mathrm{CrMo} 4$ | Einfluss der induktiven Wärmebehandlungsparameter auf die mechanischen Eigenschaften von 50CrMo4. HTM - J Heat Treat Mater 74:366-379. https://doi.org/10.3139/105.110398

6. Vieweg $A E$, Ressel $G$, Raninger $P$, et al (2018) Comparing fast inductive tempering and conventional tempering: Effects on microstructure and mechanical properties. Metall Res Technol 115:. https://doi.org/10.1051/metal/2018015

7. Kaiser D, Damon J, Mühl F, et al (2020) Experimental investigation and finite-element modeling of the short-time induction quench-and-temper process of AISI 4140. J Mater Process Technol 279:. https://doi.org/10.1016/j.jmatprotec.2019.116485

8. Fomin A, Fomina M, Koshuro V, Rodionov I (2019) Composite metal oxide coatings on chromium-nickel stainless steel produced by induction heat treatment. Compos Struct 229:. https://doi.org/10.1016/j.compstruct.2019.111451

9. Yoshida W (2020) Residual Stress Control on Bearing Steel by Surface Cooled Induction Heating Fast Tempering. J Mater Eng Perform. https://doi.org/10.1007/s11665-020-04756-3

10. Fanetti M (2010) Localized heat treatments, modality of performance and applications | Trattamenti termici localizzati, modalità di esecuzione ed applicazioni. Riv Ital della Saldatura 62:171-175

11. Mazukhina EA, Priymak EY, Gryzunov VI, Firsova N V (2015) Choice of heat treatment regimes for welded joints of preliminarily mechanically hardened steels. Met Sci Heat Treat 57:91-96. https://doi.org/10.1007/s11041-015-9842-1

12. Guo FJ, Wang YF, Wang MS, et al (2020) Hetero-deformation induced strengthening and toughening of pure iron with inverse and multi-gradient structures. Mater Sci Eng A 782:. https://doi.org/10.1016/j.msea.2020.139256

13. Bao L, Liu W, Li Q, et al (2019) Experimental Investigation on Partition Induction Heating of High-Strength Boron Alloyed Steel Blanks. Steel Res Int 90:. https://doi.org/10.1002/srin.201900255

14. Su C-W, Zhao L, Bai Y, et al (2019) Microhardness improvement of Ni-W/SiC composite coatings by high frequency induction heat treatment. J Electrochem Soc 166:D301--D307. https://doi.org/10.1149/2.0661908jes 
15. Liu $Y$, Xue $X$, Fang $H$, et al (2020) The growth behavior of columnar grains in a TiAl alloy during directional induction heat treatments. CrystEngComm 22:1188-1196. https://doi.org/10.1039/c9ce01631g

16. Smolyanov IA, Kotlan V, Doležel I (2020) Optimal heat induction treatment of titanium alloys. COMPEL - Int J Comput Math Electr Electron Eng 39:53-65. https://doi.org/10.1108/COMPEL05-2019-0212

17. Zhang P, Li Y, Lei Q, et al (2020) Microstructure and mechanical properties of a CuNiTi alloy with a large product of strength and elongation. J Mater Res Technol 9:2299-2307. https://doi.org/10.1016/j.jmrt.2019.12.061

18. Alzamani M, Jafarzadeh K, Fattah-Alhosseini A (2019) ElS study of oxidation heat-treatment effects on corrosion behavior of Ni10Cu11Fe6Al metallic inert anode inside molten calcium chloride salt. Mater Corros 70:605-611. https://doi.org/10.1002/maco.201810417

19. Jankejech P, Fabian P, Broncek J, Shalapko $Y(2016)$ Influence of tempering on mechanical properties of induction bents below $540^{\circ} \mathrm{C}$. Acta Mech Autom 10:81-86. https://doi.org/10.1515/ama-2016-0013

20. Km K-T, Shin M-C, Chang H-Y, et al (2016) Effects of induction heat bending and heat treatment on the boric acid corrosion of low alloy steel pipe for nuclear power plants. J Korean Inst Met Mater 54:817-825. https://doi.org/10.3365/KJMM.2016.54.11.817

21. Li L, Zheng J, Wang C (2020) Fatigue behavior improvements of laser-induction hybrid welded S690QL steel plates. Opt Laser Technol 126:. https://doi.org/10.1016/j.optlastec.2020.106101

22. Vollmer M, Baunack D, Janoschka D, Niendorf T (2020) Induction Butt Welding Followed by Abnormal Grain Growth: A Promising Route for Joining of Fe-Mn-Al-Ni Tubes. Shape Mem Superelasticity 6:131-138. https://doi.org/10.1007/s40830-019-00261-2

23. Oliver WC, Pharr G (1992) An improved technique for determining hardness and elastic modulus using load and displacement sensing indentation experiments. J Mater Res 7:15641583. https://doi.org/10.1557/JMR.1992.1564

24. ASTM E2546-15 (2015) Standard Practice for Instrumented Indentation Testing. In: ASTM International. West Conshohocken PA

25. ISO 14577-1:2015 (2015) Metallic materials - Instrumented indentation test for hardness and materials parameters - Part 1: Test method. In: International Organization for Standardization

26. (2020) Anton Paar - Instrumented Indentation Tester

27. (2020) NANOVEA - Mechanical Testers

28. Sutton MA, Orteu J-J, Schreier HW (2009) Image Correlation for Shape, Motion and Deformation Measurements. Springer-Verlag, New York

29. Chakrabarty J (2006) Theory of Plasticity, 3rd ed. Elsevier Butterworth-Heinemann, Burlington, MA, USA 